\title{
Accessory Cusp of Tricuspid Valve-Anatomical, Clinical, and Embryological Aspects
}

\section{Seema Sehmi}

\begin{abstract}
Aim: The aim of this study is to report the rare anomaly of accessory cusp present in the tricuspid valve.

Background: The right atrioventricular valve also known as the tricuspid valve allows the blood to flow from the right atrium to the right ventricle. Tricuspid diseases although rare but tricuspid valve regurgitation, stenosis, and Ebstein's anomaly are included.

Case description: During routine dissection of normal adult formalized heart for undergraduate medical students at the Department of Anatomy, SGRD Medical College, Amritsar, we noticed four cusps of the right atrioventricular valve. They were anterior, septal, posterior, and accessory valves which were anterolateral in position. The septal cusp was the largest of all. The papillary muscles were anterior, posterior, and septal and one for the accessory cusp.
\end{abstract}

Conclusion: This anomaly is important for the cardiothoracic surgeon for correcting their defects.

Keywords: Accessory, Anterolateral, Septal, Tricuspid.

How to cite this article: Sehmi S. Accessory Cusp of Tricuspid Valve-Anatomical, Clinical, and Embryological Aspects. Curr Trends Diagn Treat 2018;2(2):115-117.

Source of support: Nil

Conflict of interest: None

\section{BACKGROUND}

The right atrioventricular valve is a heterogeneous structure having three valves: anterior (superior), posterior (inferior), and septal..$^{1}$ Sometimes the number of cusps may vary or accessory valves are seen in between the main cusps. The valve is a fold of endocardium strengthened by the fibrous tissue. ${ }^{2}$ Accessory tricuspid valve is a rare congenital cardiac anomaly that is seen commonly in children with complex congenital anomalies. ${ }^{3}$ Two main types have been defined: mobile and fixed. The

\section{Professor}

Department of Anatomy, Sri Guru Ram Das Institute of Medical Sciences \& Research, Amritsar, Punjab, India

Corresponding Author: Seema Sehmi, Professor, Department of Anatomy, Sri Guru Ram Das Institute of Medical Sciences \& Research, Amritsar, Punjab, India, Phone: +91 9914754354, e-mail: drseema16@gmail.com mobile type is a parachute-like leaflet floating freely in the right ventricle via a long chordae. The fixed type is firmly anchored to the interventricular septum by a short chordae. ${ }^{4}$ Initially, the accessory cusp of the tricuspid valve was described by Tandler, ${ }^{5}$ Testut and Laterjet, ${ }^{6}$ and Jastrzebski. ${ }^{7}$ Diseases of the tricuspid valve are less common though they are associated with mitral valve or aortic valve diseases. ${ }^{8}$ Ebstein's anomaly is the commonest congenital anomaly of the tricuspid anomaly in which there occur downward displacement of the basal attachment of the posterior and septal leaflets. ${ }^{9}$ Tricuspid valvular diseases usually require valvuloplasty or replacement and require a detailed anatomical knowledge of valvular cusps for the preparation of prosthesis. ${ }^{10}$

\section{CASE DESCRIPTION}

The present case was an adult formalized heart at the Department of Anatomy, SGRD Medical College, Vallah. The tricuspid valve was exposed from the atrial side after giving an incision from the superior vena cava to the inferior vena cava. The tricuspid cusps were studied for its cusps and the presence or absence of any accessory cusps was noted. The number of cusps, shapes, length, and height of all the cusps was noted. The tricuspid valve showed anterior, septal, and posterior cusps, and, in addition, there is an accessory cusp which was anterolateral in position (Fig. 1). The length of the cusp means the measurement of distance of attachment of the cusps to the annulus. The height of the accessory cusp was measured from the free margin to the attached with the help of vernier callipers. The length of the accessory cusp was $16.44 \mathrm{~mm}$ and the height was $14.3 \mathrm{~mm}$. The ventricular surface of the tricuspid valve was studied by extending the earlier incision further vertically downwards along the right border of the right ventricle just above the apex of the heart. Papillary muscles and chordae tendinae were identified and their number was noted. The presence of any accessory papillary muscle was also noted. The right atrioventricular valve had four cusps that project into the right ventricle: anterior, posterior, septal, and an accessory valve ka anterolateral cusp. Inspection of the interior of the right ventricle showed conical muscular projections which were papillary muscles and were four in number: anterior, posterior, septal, and one accessory 


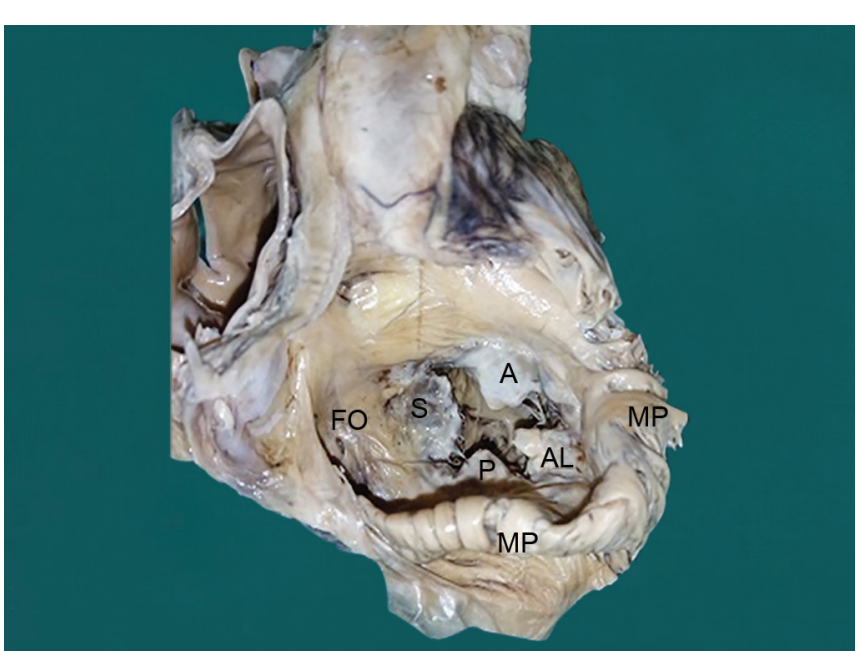

Fig. 1: An accessory cusp (anterolateral $=A L$ ) present in the tricuspid valve of a formalized adult heart in addition to anterior $(A)$, posterior $(P)$, and septal $(\mathrm{S})$ cusps is shown. FO, fossa ovalis; MP, musculi pectinati

papillary muscle attached to the anterolateral accessory cusp (Fig. 2). The anterior papillary muscle arose from the anterior wall of the right ventricle. The posterior papillary muscle arose from the posterolateral wall of the right ventricle. The septal papillary muscle was from the septal wall. The accessory papillary muscle arose from the anterolateral wall of the right ventricle. All the papillary muscles were single headed. No other cardiac abnormality was found.

\section{DISCUSSION}

The atrioventricular valve develops by the excavation of the supporting ventricular myocardium at the fifth week of the intrauterine life. The cavitation of the ventricular wall forms a sponge work of muscle bundles.

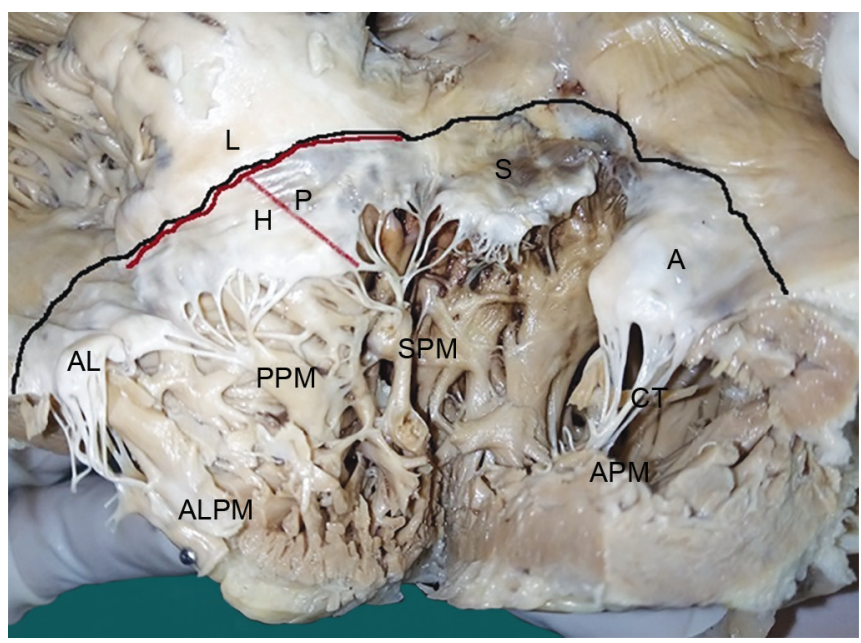

Fig. 2: Interior of the right ventricle with anterior cusp (A), posterior cusp $(P)$, septal cusp $(S)$, anterolateral cusp $(A L)$, anterior papillary muscle (APM), posterior papillary muscle (PPM), septal papillary muscle (SPM), and anterolateral papillary muscle (ALPM) is shown. Black line shows the attachment of the tricuspid valve with the length of posterior cusp $(L)$ and the height of posterior cusp $(H)$ is shown with red line
Table 1: The percentages of cases with four cuspidal tricuspid valve given by different authors

\begin{tabular}{|c|c|c|c|}
\hline S. no. & Various studies & Year & $\begin{array}{l}\text { Cases with four } \\
\text { cuspidal tricuspid } \\
\text { valve (\%) }\end{array}$ \\
\hline 1 & Sutton et al. ${ }^{15}$ & 1995 & 8 \\
\hline 2 & Kocak et al. ${ }^{14}$ & 2004 & 10 \\
\hline 3 & Skwarek et al. ${ }^{13}$ & 2007 & 36.15 \\
\hline
\end{tabular}

Some of them become trabeculae carneae and the remaining form the papillary muscles. The complete atrioventricular valve is fully developed by the eighth week of the intrauterine life. ${ }^{11}$ The four cuspidal tricuspid valve is the most common anomaly of the accessory tricuspid valve cusps. ${ }^{12}$ The frequency of the four cuspidal tricuspid valve is $36.15 \%$ by Skwarek et al., ${ }^{13}$ $10 \%$ by Kocak et al., ${ }^{14}$ Chauhan et al., ${ }^{12}$ and $8 \%$ by Sutton et al. ${ }^{15}$ (Table 1 ). A study by Gerola et al. ${ }^{16}$ showed that the commonest pattern for the tricuspid valve was three cusps, while four cusps if present were classified as anterolateral in position. Similarly, Ankolekar et al. ${ }^{17}$ reported a case with an accessory valve which was anterolateral in position and was also seen in the present case. The present case had the shape of the anterior, posterior, and anterolateral cusps as triangular except the septal cusp which was quadrilateral in shape which is contrary to the Skwarek et al. ${ }^{13}$ who gave the triangular shape of all the cusps and Motabagani et al. ${ }^{18}$ who gave the most common shape of the septal cusp as semicircular. In the present case, the septal cusp was the largest in size followed by anterior, anterolateral, and posterior cusps which was in contrast to the study done by Shwarek et al. ${ }^{13}$ and Motabagani et al. ${ }^{18}$ in which the anterior cusp was the largest of all the cusps. The height of the accessory cusp in the present study was $14.3 \mathrm{~mm}$ but Chauhan et al. ${ }^{12}$ gave the mean height of the accessory valve as $15.60 \mathrm{~mm}$ and Skwarek et al. ${ }^{13}$ showed the mean height as $14.88 \mathrm{~mm}$. In most of the cases, the accessory cusp of the tricuspid valve was associated with other cardiac malformations. The treatment included is either the chordal replacement or augmentation with the expanded polytetra fluoroethylene suture. ${ }^{19}$ The present heart under study had no other valvular or muscular malformation.

\section{CONCLUSION}

The present case reported a rare variation of the tricuspid valve having an accessory cusp which was anterolateral in the position with an independent papillary muscle arising from the anterolateral wall of the right ventricle. This variation is important not only to understand the normal functions of the tricuspid valve but also to improve the understanding of the pathophysiological mechanism underlying the various tricuspid valve diseases and help to improve the surgical treatment related to it. 


\section{REFERENCES}

1. Silver MD, Lam JHC, Ranganathan N, et al. Morphology of the human tricuspid valve. Circulation 1971;43:333-348.

2. Walls EW. The blood vascular and lymphatic systems. In: Romanes GJ, ed. Cunningham's Textbook of Anatomy. New York: Oxford University Press, 1995; pp.871-1008.

3. Xanthos T, Dalivigkas I, Ekmektzoglou KA. Anatomic variations of the cardiac valves and papillary muscles of the right heart. Ital J Anat Embryol 2011;116:111-126.

4. Faggian G, Frescura C, Thiene G, et al. Accessory tricuspid valve tissue causing obstruction of the ventricular septal defect in tetralogy of Fallot. Br Heart J 1983;49:324-327. doi: 10.1136/hrt.49.4.324.

5. Tandler J. Anatomie des Herzens. In: Van Bardeleben K, ed. Handbuch der Anatomie des Menchen. Jena: G. Fischer, 1913; pp.84-90.

6. Testut L, Latarjet A. Traite $\mathrm{d}^{\prime}$ anatomie humaine. Paris: G. Doin Cie, 1948; vol. II.

7. Jastrzebski C. O zmiennosci ksztattu zastawki trojdzielnej serca I o otworach wrodzonych w jej platkach. Kosmos Seria A Biologia 1926;51:191.

8. Shah PM. The heart. Tricuspid valve, pulmonary valve and multivalvular disease. 13th ed. McGraw Hill Medical, 2011; p.1748.

9. Lang D, Oberhoffer R, Cook A, et al. Pathologic spectrum of malformations of the tricuspid valve in prenatal and neonatal life. J Am Coll Cardiol 1991;17:1161-1167.

10. Aoyagi S, Maruyama H, Akasu K, et al. Isolated tricuspid valve regurgitation resulting from severe annular dilatation: case report. J Heart Valve Dis 1999;8(4):457-459.
11. Moore KL. Clinically oriented anatomy. 4th ed. Baltimore: Lippincott William \& Wilkins, 1992; pp.111-127, ch. 1.

12. Chauhan KR, Udainia A, Mehta CD, et al. Study of incidence of an abnormal tricuspid valve in the human cadaveric heart. Natl J Med Res 2014;4(3):238-240.

13. Skwarek M, Hreczecha J, Dudziak M, et al. The morphology and distribution of the tendinous chords and their relation to the papillary muscles in the tricuspid valve of the human hearts. Folia Morphol 2007;66:314-322.

14. Kocak A, Govsa F, Aktas EO, et al. Structure of the human tricuspid valve leaflets and its chordae tendineae in unexpected death. A forensic autopsy study of 400 cases. Saudi Med J 2004;25(8):1051-1059.

15. Sutton JP, Ho SY, Vogel M, et al. Is the morphologically right atrioventricular valve tricuspid. J Heart Valve Dis 1995;4(6): 571-575.

16. Gerola LR, Wafae N, Vieira MC, et al. Anatomic study of the tricuspid valve in children. Surg Radial Anat 2001;22(3): 149-153.

17. Ankolekar VH, Das A, Dsouza A, et al. Tetracuspid right atrioventricular valve: a case report. Int J Health Sci Res 2014;4(11):253-255.

18. Motabagani MAB. Comparative anatomical, morphometric and histological studies of the tricuspid valve-complex in human and some mammalian hearts. J Anat Soc Ind 2006;55(1):1-23.

19. Yoon A, Shaqra H, Levin M, et al. Accessory tricuspid valve leaflet in an asymptomatic adult. Tex Heart Inst J 2008;35: 327-328. 